\title{
Electrochemical and electrophysical nondestructive testing methods for protective polymer coatings
}

\author{
V.A. Golovin* and S.A. Dobriyan \\ A.N. Frumkin Institute of Physical Chemistry and Electrochemistry, Russian Academy of \\ Sciences, Leninsky pr. 31, 119071 Moscow, Russian Federation \\ E-mail: golovin@rocor.ru
}

\begin{abstract}
Based on own and literature data, the possibility of using various electrochemical and electrophysical nondestructive testing methods, including their use for monitoring the state of the coating film and corrosion of the metal being protected, was analyzed for protective polymer coatings in various corrosive environments. Primary attention is paid to the evaluation of the capabilities of the electrochemical impedance method (EIS). The methodological aspects are considered and the validity of the choice of equivalent circuits for various types of polymer protective coatings on various substrates is analyzed. The results of evaluating the sorption of a corrosive medium based on changes in the coating capacitance on inert and corrosive substrates are considered. Models describing the defects of thin-layer paint and thick-layer protective polymer coatings were estimated. It was shown that there is a relationship between the resistance and the inverse capacitance of the Faraday process for thin-layer paint coatings. However, this relationship is more complicated than that predicted by the model in the works by MansfeldTitz and is non-linear over the entire time range. More promising are the results of testing the model of sub-film corrosion under thick-layer and multilayer protective coatings, for which the through porosity is insignificant, which allows one to uniquely associate the variation in the integral resistance of the Faraday process, $R_{\mathrm{dl}}$, with the fraction of sub-film corrosion. It seems that the results of this work may be useful for devices for the nondestructive EIS analysis of the health of operating protective coatings that are currently being developed.
\end{abstract}

Keywords: corrosion protection, polymer protective coatings, sorption, under-film corrosion, EIS.

Received: June 16, 2020. Published: September 14, 2020

doi: $\underline{10.17675 / 2305-6894-2020-9-3-18}$

\section{Introduction}

Corrosion is a considerable problem in chemical, power, oil and gas, aerospace, and other industries, and also in municipal engineering and in transport. According to the data of the World Corrosion Organization (WCO), the total direct annual economic damage due to corrosion exceeds $\$ 1.8$ trn [1].

At present, the most popular method of corrosion protection in up to $70 \%$ of the overall scope of corrosion protection of metal surfaces [2] is the application of paint and polymer 
coatings [3]. The economic performance also favors the use of such coatings. In fact, the costs of protection by coatings $\left(\$ 500 / \mathrm{m}^{2}\right)$ are much smaller than the costs of stainless steel $\left(\$ 3000 / \mathrm{m}^{2}\right)$ and reinforced composites $\left(\$ 1000 / \mathrm{m}^{2}\right)$.

The use of polymer coatings for protection in highly corrosive media is gaining in popularity due to the already achieved set of their performance characteristics. In most cases, the protective polymer coatings based on synthetic resins that are used in his field are thick $(0.4-2.0 \mathrm{~mm})$ multilayer systems [4].

From the physicochemical point of view, it is of crucial importance that polymer coatings of any thickness in solutions of corrosive electrolytes do not form an absolute diffusion barrier and remain penetrable for water, volatile and nonvolatile acids [5] and also contain migrating water-soluble residual process-related impurities. Since the rates of penetration of water and electrolytes into polymers differ considerably, the composition of the electrolyte in a coating and on a substrate being protected can differ from the composition of the outside solution. It was also found that cation and anion permeation is selective for acid salts [6].

In view of this, a "metal-coating-electrolyte" system should be considered as a system with specific electrochemical properties due to the presence of a polymer coating film on the metal surface that is selectively permeable for electrolytes [7].

For this reason, electrochemical and electrophysical methods [8,9] are most informative and find extensive use as methods for nondestructive testing of protective coatings in corrosive media.

It is the first paper in a series of publications on nondestructive testing and electrochemical study of protective properties of polymer coatings.

\section{The main methods for the electrochemical and electrophysical monitoring of protective coatings}

\subsection{Monitoring the state of the coating film}

The possibility to monitor the state of a coating film relies on the fact that the properties of a metal-coating-electrolyte system are largely determined by the electric and electrochemical properties of the polymer coating film. For instance, a decrease in electric resistance to the reduced resistance of fracture (GOST 9.083-78) is used as a criterion of coating failure (degradation). Other standard characteristics in use include the dielectric loss tangent and ratio of capacitances of a metal-coating-electrolyte system measured at different $\mathrm{AC}$ frequencies $\left(K_{\mathrm{f}}\right)$. The coefficient $K_{\mathrm{f}}$ grows with an increase in the paint film porosity, as the electrochemical capacitance strongly depends on the current frequency, while the electric component is small and does not depend on the frequency [10]). Therefore, the $K_{\mathrm{f}}$ value can also be used to estimate the level of coating degradation during tests and exposure to an environment [10]. 


\subsection{Monitoring the substrate corrosion}

Methods for nondestructive monitoring of substrate corrosion are obviously of particular interest since the primary function of protective polymer coatings is to prevent or reduce the corrosion of a metal being protected.

Initially, the methods considered as promising for monitoring metal corrosion under a paint film were based on the estimation of changes in the electric resistance of a thin metal film applied on a glass plate before applying a coating to be studied (GOST 9.083-78). It is obvious, however, that as the composition and structure of a sputter-deposited iron film differ from the characteristics of real steels and alloys, the method cannot be considered fully adequate. Moreover, this method cannot be used for the direct nondestructive monitoring of vessel wall corrosion under industrial conditions.

\subsubsection{Eddy current method}

Of doubtless interest, especially for industrial application, is the method of eddy current monitoring of the corrosion damage of a substrate under a coating [11].

The prospects of the matrix eddy current method are due to the fact that its principles have been extensively developed in recent years [12-14].

It is known that the method under consideration employs the effect of eddy currents formed in a conductive sample. They are excited in a test object by an inductance coil through which AC current is flowing. The receiver is another coil for measuring the EMF created by the secondary magnetic field generated by Foucault eddy currents.

This method is widely employed to estimate tube corrosion. In this case, an axial through probe is used with a converter consisting of two inductance coils located along the tube axis [14]. This probe type is used for estimating the integral characteristics of the residual tube wall thickness, but it does not allow local corrosion pits to be estimated.

A matrix converter (Figure 1) contains 16 or 32 pairs of inductance coils located along the probe circumference. The values of the amplitude and phase of the secondary electric signal in the measurement coils obtained after processing allow conclusions to be made concerning the continuity of each of the $N$ tube cross-section sectors. This technology can be used to measure both the extent of corrosion damage and the size of individual corrosion defects.

Thirty-two pairs of measurement coils were contained in a matrix eddy current converter used in [11] for testing subfilm corrosion of painted heat-exchange tubes with a diameter of $26 \mathrm{~mm}$, which provided the coverage of an approximately $2.5 \mathrm{~mm}$ long tube sector per coil. 


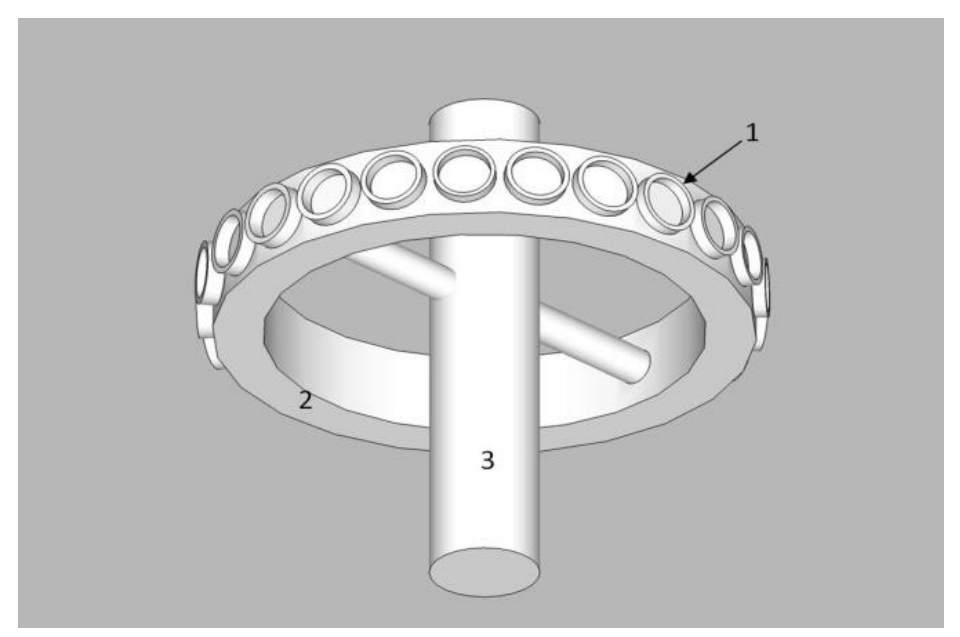

Figure 1. Schematic diagram of a matrix eddy current converter for monitoring heat-exchange tubes: (1) circumferential doubled inductance coils; (2) base; (3) tubular shaft for moving along the tube.

An advantage of the eddy current method is that it is nondestructive and allows one to monitor the total and local corrosion both under laboratory and industrial conditions, and can be used as a basis for predicting the remaining lifetime of both a substrate and a coating [15].

However, this method has certain limitations related to the substrate type, particularly for substrates with ferromagnetic properties.

\subsection{Potential measurement methods}

The method of measuring the potentials of a substrate under a coating is widely used in laboratory tests. However, considering the above data that the composition of the inner solution in a coating and at the interface with the substrate differs from the composition of the outer electrolyte for insulating protective coatings, interpretation of the measured potentials may be controversial. At the same time, the method yields interesting comparative results on different metallic substrates (active and inert) [16], which allows estimating the contributions of insulating and adhesion layers.

Methods of measuring local currents (SVET) and potentials (SIET) on a coating surface were developed lately [17], though their application range is still limited to laboratory studies of comparatively thin coatings [18].

The vibrating electrode technique (SVET) [19] is based on measuring the local changes in current density due to the difference in potentials between the anodic and cathodic regions on a surface being studied [20,21].

Local potentials can also be measured using ion-selective electrodes. This method provides information on the local activity (or concentration) of certain solution ions (e.g., $\mathrm{H}^{+}$) and thus allows estimating the changes in the acid-alkali balance owing to an electrochemical process, including local corrosion [22, 23]. 
It has been shown [24] that a combination of the above local methods allows identifying burning defects in a coating and can also be used to estimate the efficiency of inhibited coatings with a self-recovery effect.

\subsection{Conclusion}

Thus, the majority of the methods under consideration provide baseline information, but can mostly (to the exclusion of the eddy current test method) be used only in laboratory tests.

Of the methods that can currently be used in practice, the electrochemical impedance spectroscopy (EIS) method may be distinguished. EIS is suitable for various substrates, including, in the first place, the most abundant steel substrates. It can potentially provide miscellaneous information both about a coating and the coating/metal interface.

It is important to note the already implemented possibility of using the EIS method under industrial conditions, as in [25] where a miniature EIS sensor for the assessment of the initial stages of coating degradation is reported. The results obtained allowed calculating the electrochemical parameters of coatings, though the authors confined themselves to the analysis of the basic parameters.

\section{The electrochemical impedance spectroscopy (EIS) method}

The EIS method was first suggested in the eighties of the 20th century for the study of coatings [26], but its use was long limited due to the high cost of the instruments. At present, many manufacturers offer this equipment, which promoted the popularity of the method.

The EIS method became most popular in studies of various paint and polymer coatings [9, 27-29], as it provides information both about a coating layer and the processes on the surface of the metal substrate being protected.

\subsection{Methodical basics of EIS}

To date, methodical basics have been formulated both for samples with polymer coatings, equipment, measurement range, on the one hand, and presentation and processing of data, including the choice of equivalent circuits, on the other hand [30-32].

At the same time, as the methods were improved and results were accumulated, it became imperative to modify the complex techniques and elaborate the optimum methods of data processing. This is especially important for studies in corrosive media and for composite coatings with electrochemically active additives [33].

\subsection{Methods of EIS data presentation}

Typical EIS plots for protective polymer coatings of various types in some corrosive media, such as single-layer paint coating in $\mathrm{NaCl}$ solution (Figures 2 and 3), multilayer thick coating in sulfuric acid (Figures 4 and 5), Zn-filled primer coating (Figures 6 and 7), and a composite coating (Figures 8-10) are presented below. 


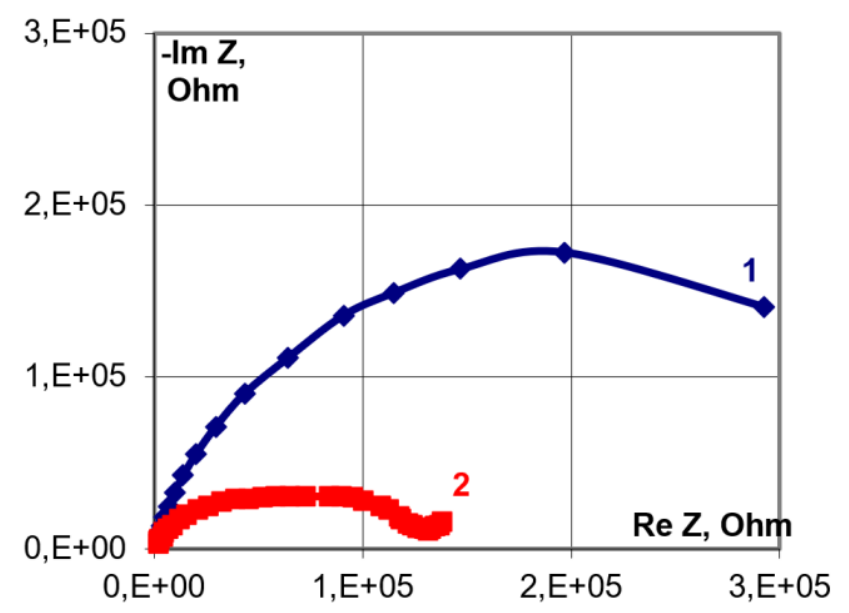

Figure 2. Impedance hodographs $(\operatorname{Im}|Z|=f(\operatorname{Re}|Z|))$ of water-borne $\mathrm{R}-5095$ epoxy coating applied directly on a steel substrate after exposure to $3 \% \mathrm{NaCl}$ at $25^{\circ} \mathrm{C}$ for: (1) 30 days; (2) 200 days.
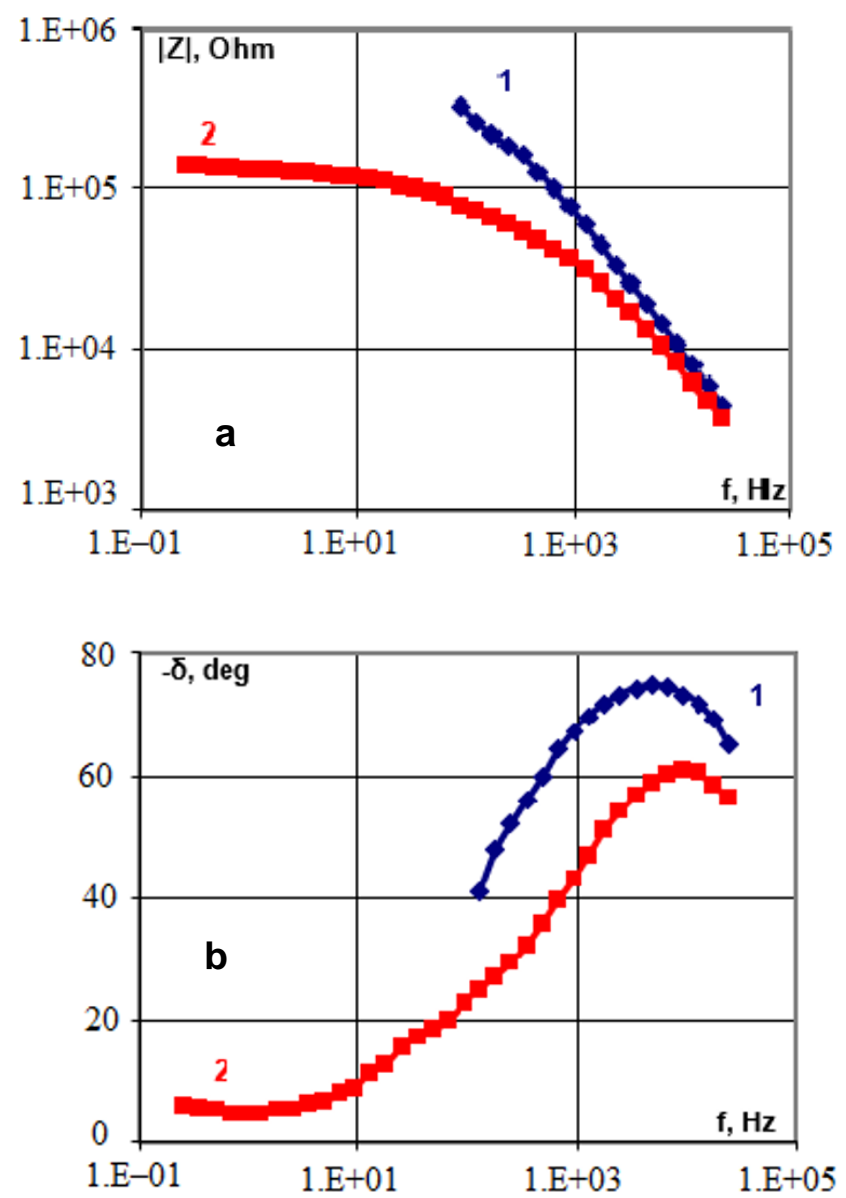

Figure 3. (a) Frequency dependence of impedance module $|Z|$ and (b) loss angle $\delta$ of waterborne R-5095 epoxy coating applied on a steel substrate after exposure to $3 \% \mathrm{NaCl}$ at $25^{\circ} \mathrm{C}$ for (1) 30 days; (2) 200 days. 

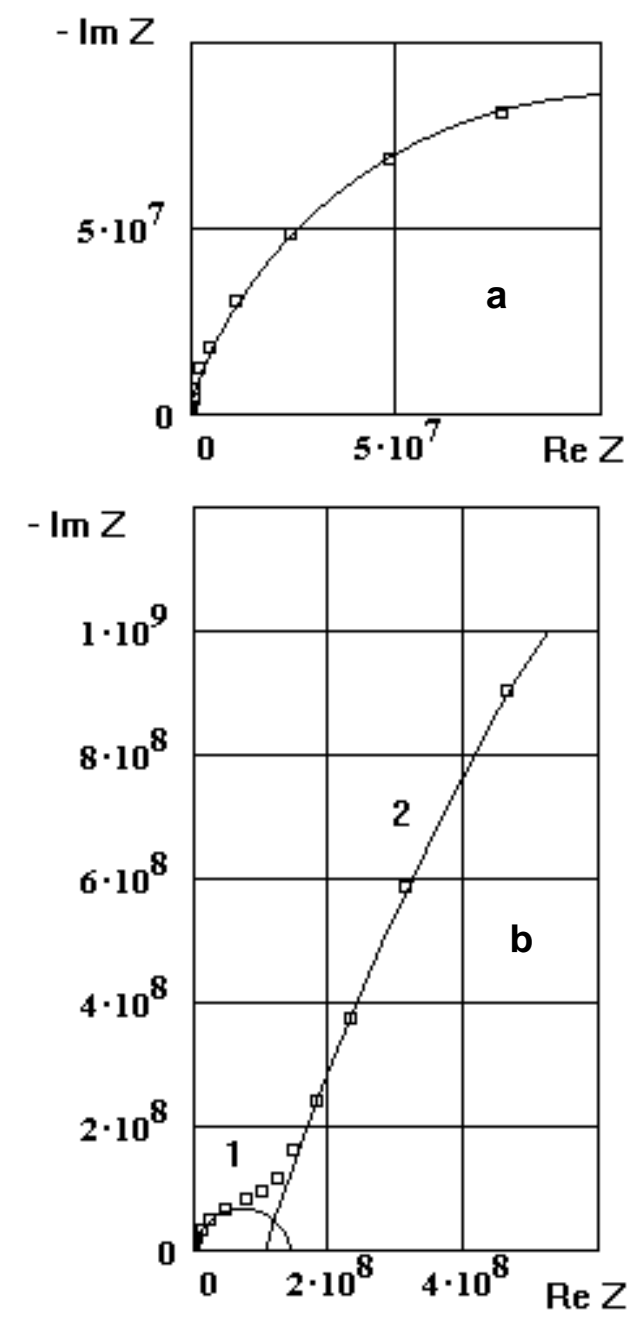

Figure 4. High-frequency $\left(10^{4}\right.$ to $\left.5 \cdot 10^{2} \mathrm{~Hz}\right)$ branch (a and region $1 \mathrm{in}$ b) and (b) full $\left(10^{4}\right.$ to $\left.10^{-2} \mathrm{~Hz}\right)$ impedance hodograph $(\operatorname{Im}|Z|=f(\operatorname{Re}|Z|))$ of a three-lay er epoxy coating applied directly on a steel substrate after exposure to $30 \% \mathrm{H}_{2} \mathrm{SO}_{4}$ at $20^{\circ} \mathrm{C}$ for $962 \mathrm{~h}$. The coating thickness is $612 \mu \mathrm{m}$ [54].

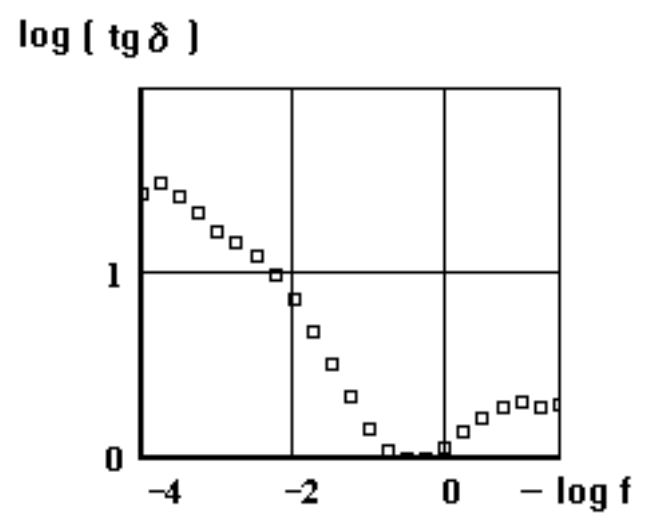

Figure 5. Frequency dependence of the tangent of dielectric loss angle $\delta$ for a three-layer epoxy coating applied directly on a steel substrate after exposure to $30 \% \mathrm{H}_{2} \mathrm{SO}_{4}$ at $20^{\circ} \mathrm{C}$ for $962 \mathrm{~h}$. The coating thickness is $612 \mu \mathrm{m}$ [54]. 


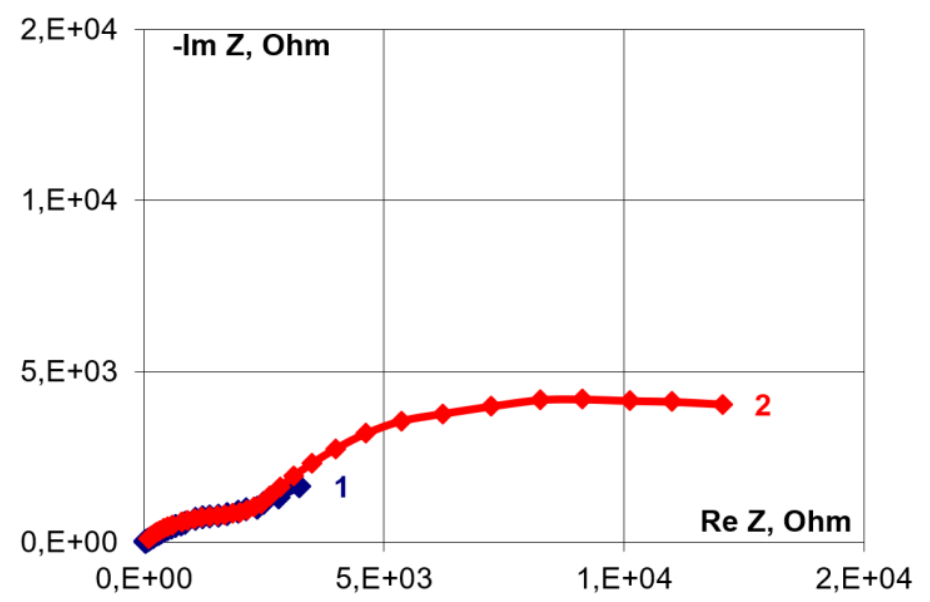

Figure 6. Impedance hodographs $(\operatorname{Im}|Z|=f(\operatorname{Re}|Z|))$ of an organic solvent-borne Zn-protector M-01 primer applied on a steel substrate after exposure to $3 \% \mathrm{NaCl}$ at $25^{\circ} \mathrm{C}$ for (1) 30 days; (2) 100 days.
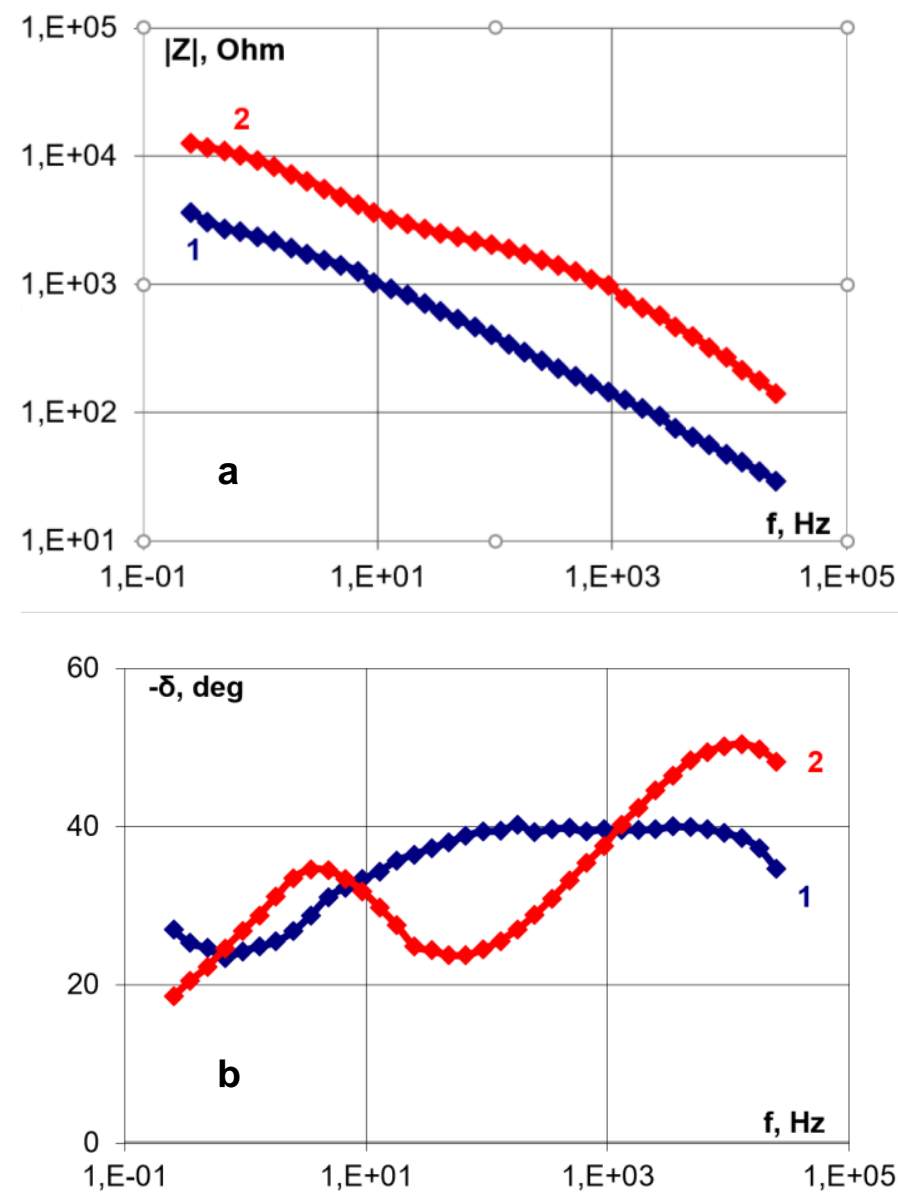

Figure 7. Frequency dependence of (a) impedance module $|Z|$ and (b) loss angle $\delta$ of an organic solvent-borne $\mathrm{Zn}$-protector M-01 primer applied on a steel substrate after exposure to $3 \% \mathrm{NaCl}$ at $25^{\circ} \mathrm{C}$ for (1) 30 days; (2) 100 days. 


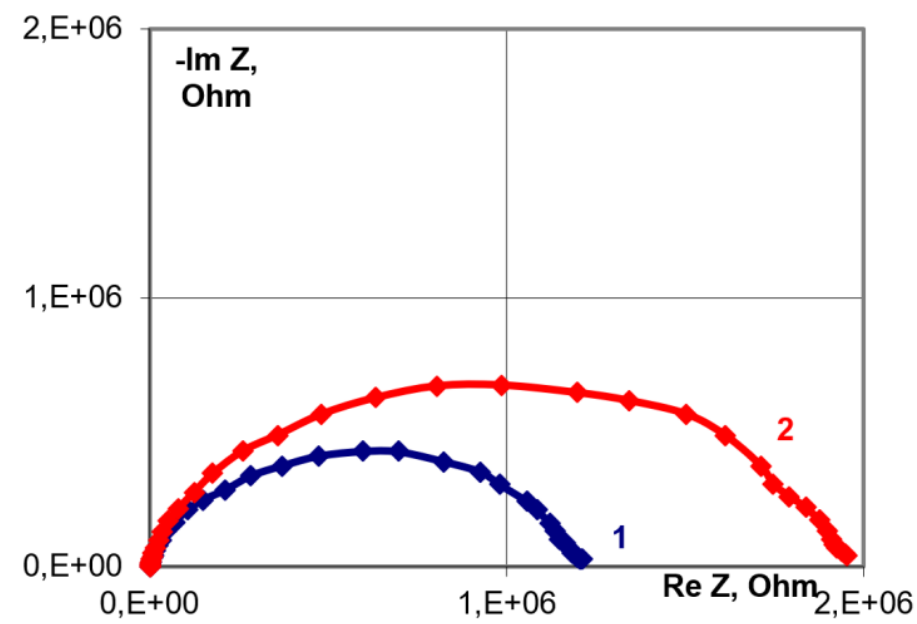

Figure 8. Hodographs $(\operatorname{Im}|Z|=f(\operatorname{Re}|Z|))$ of a system of (water-based M-017B primer and water-based R-5095 epoxy coating) applied on a steel substrate after exposure to $3 \% \mathrm{NaCl}$ at $25^{\circ} \mathrm{C}$ for (1) 30 days; (2) 200 days.
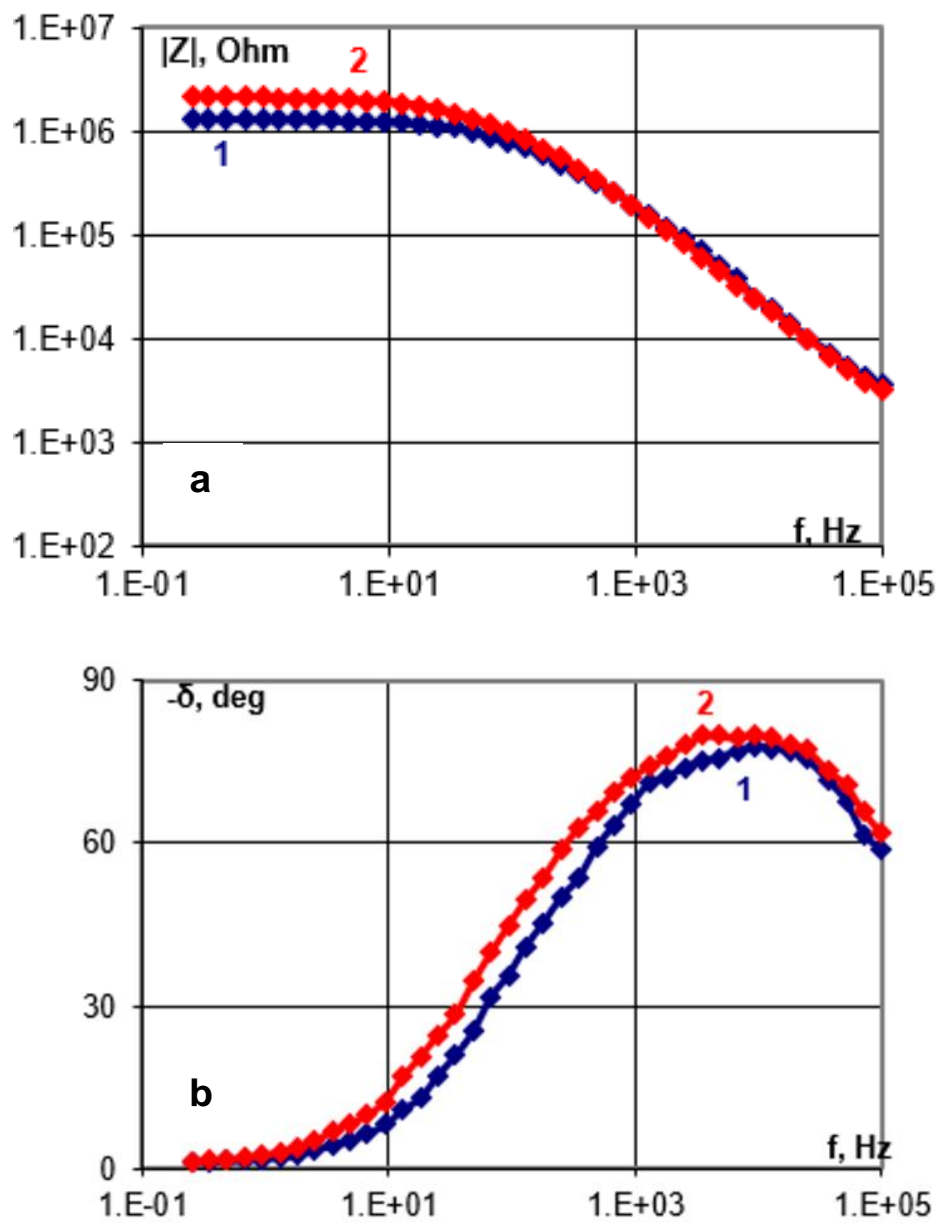

Figure 9. Frequency dependence of (a) impedance module $|Z|$ and (b) loss angle $\delta$ of a system of (water-based M-017B primer and water-based R-5095 epoxy coating) applied on a steel substrate after exposure to $3 \% \mathrm{NaCl}$ at $25^{\circ} \mathrm{C}$ for (1) 30 days; (2) 200 days. 

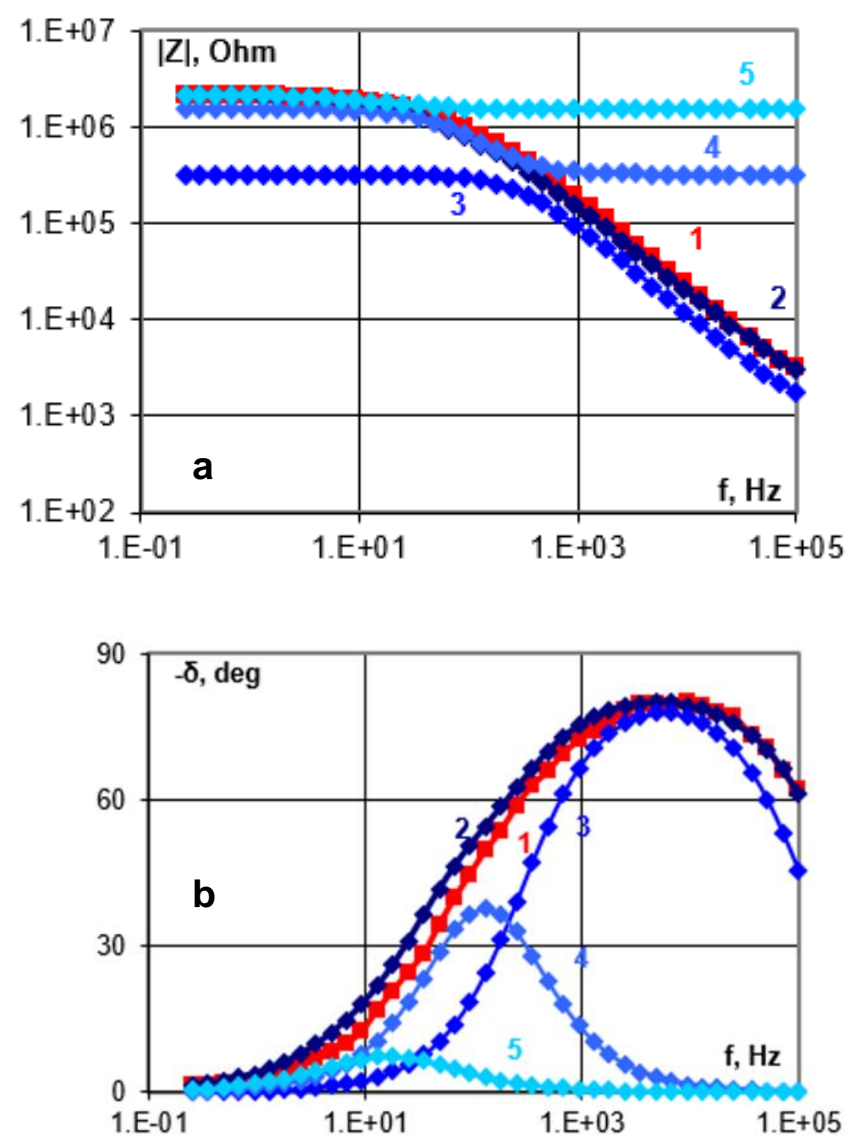

Figure 10. Frequency dependence of (a) impedance module $|Z|$ and (b) loss angle $\delta$ of a system of M-017B primer + R-5095 coating on a steel substrate after exposure to $3 \% \mathrm{NaCl}$ for 200 days and an example of their calculation with breakdown of the calculated curves into components: (1) experiment; (2) integral calculated curves according to the Voigt circuit (Figure 18); (3) high-frequency component; (4) medium-frequency component; (5) lowfrequency component.

One can see that the most informative data presentation is determined both by the properties of a system in its initial state and the character and range of variation of parameters in case of penetration of corrosive media, owing to which it is unreasonable to choose any single variant. This is especially important for high-ohmic systems where impedance changes by several orders of magnitude in the measured frequency range.

\subsection{Approaches to the choice of equivalent circuits}

It is now generally accepted that polymer coatings should be considered as locally nonuniform systems not only in the initial state, but also after penetration of aqueous solutions of electrolytes, with consideration for the fact that they host several charge transport and accumulation processes simultaneously.

The simulation is based on the approach using equivalent circuits (ECs) with elements representing electric equivalents of structural elements of coatings and processes. Obviously, 
the design and choice of ECs are primarily based on the physical relevancy of ECs and the possibility to describe all the kinetic stages. In the first approximation, some simplified description based on an equivalent circuit is used, and later it is elaborated with account for the data on the kinetics and additional information on the charge transport and accumulation.

All other conditions being equal, if the approximation accuracy is comparable, a simpler equivalent circuit with a smaller number of elements is preferred [33].

The simplest equivalent circuit (EC) [34] is a three-element circuit (Figure 11). Such an $\mathrm{EC}$ is suitable for describing inert thin-layer low-defect coatings on an inert substrate [35].

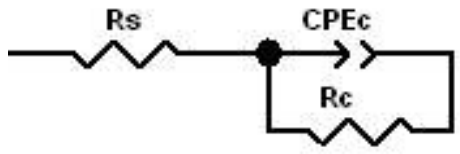

Figure 11. The simplest equivalent circuit for the simulation of the impedance of an inert coating on an inert substrate.

One can see that the circuit includes the active resistances of the solution $\left(R_{\mathrm{S}}\right)$ and of the coating $\left(R_{\mathrm{C}}\right)$ and a frequency-dependent CPE element, with its impedance described by the equation:

$$
Z(\mathrm{CPE})=Y_{0}^{-1}(j \omega)^{-n}
$$

where $Y_{0}$ is the CPE constant; $n$ is the CPE parameter; $\omega$ is the frequency $\left(\operatorname{rad} \cdot \mathrm{s}^{-1}\right)$; and $j$ is the imaginary unit $\left(j^{2}=-1\right)$.

Depending on the value of parameter $n$, the CPE element can describe the active resistance $(Z(\mathrm{CPE})=R, n=0)$, capacitance $(Z(\mathrm{CPE})=C, n=1)$, inductance $(Z(\mathrm{CPE})=L$, $n=-1)$, or Warburg impedance $(n=0.5)$.

For a capacitive CPE element, constant $Y_{0}$ is related to capacitance as follows [36, 37]:

$$
C_{\mathrm{c}}=Y_{0}\left(\omega_{m}\right)^{n-1}
$$

where $C_{\mathrm{c}}$ is the coating capacitance and $\omega_{m}$ is the angular frequency $(\omega=2 \pi f=2 \pi / \mathrm{T}[\mathrm{rad} / \mathrm{s}])$ at which the imaginary component has a maximum on the semicircle in Nyquist coordinates.

The above three-element circuit with a CPE element and one relaxation process can take into account the local nonuniformity of the coating, but it does not describe coatings with defects and pores nor the stage of subfilm corrosion development.

For typical paint coatings with defects and subfilm corrosion in the pore zone, Mansfeld suggested [27] a circuit with two characteristic time constants (relaxation times):

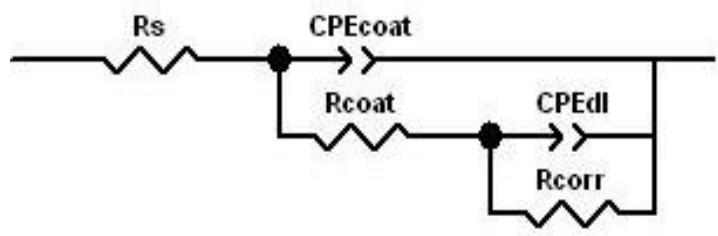

Figure 12. Mansfeld equivalent circuit for a coating with defects. 
It should be pointed out that though the above circuit (Figure 12) is used most frequently, it is not the only circuit that can be used for the description of coatings with two characteristic relaxation times. In particular, the following equivalent circuit is suggested (Figure 13) [38]:

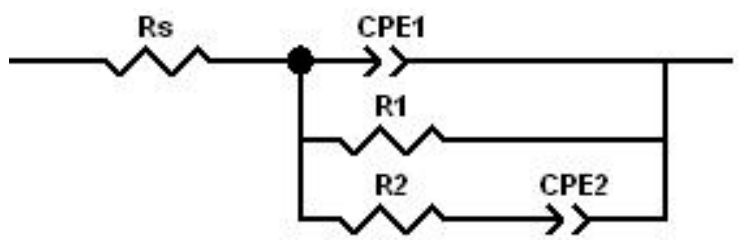

Figure 13. A possible equivalent circuit for simulation of coating impedance with two relaxation times.

There is another approach to the choice of an equivalent circuit for composite polymer coatings, which is justified in terms of physical chemistry.

It is based on the fact that there are local zones (filler and polymer base) with different conductivity in polymer composites with a dispersed filler (the most common situation for protective coatings). Such systems can be described using the serial Voigt model [39].

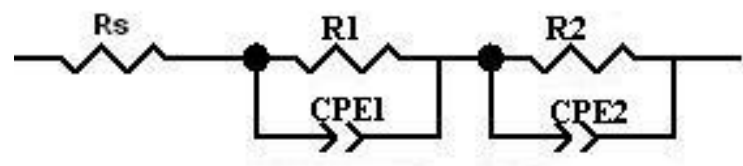

Figure 14. The Voigt equivalent circuit for a filled polymer composite containing zones with different conductivity.

Obviously, the Voigt circuit can be used for layered nonuniform composites, including protective coatings [54].

An additional argument supporting the use of the Voigt circuit is its tolerance to the quality of experimental EIS data.

It is known that Kramers-Kronig (KK) relationships can basically be used for the evaluation of the correctness of experimental data on dielectric permeability within the classical electrodynamics [40]. Accordingly, the real component can be calculated by integration of the frequency dependence of the imaginary component and vice versa. Moreover, such integration must be performed in the entire frequency range from zero to infinity. However, as experimental measurements of impedance in this range are not performed, $\mathrm{KK}$ analysis is carried out in practice by simulation of spectral data using a model. For this reason, simple equivalent circuits with serially connected Voigt elements are preferable (Figure 14). For example, when a serial circuit with Voigt elements $(R \| \mathrm{CPE})_{\mathrm{m}}$ is used, a finite number of elements is sufficient; ideally, it can be equal to the number of linear regions in the Bode diagram $(|Z|(f))$. Such a model is KK-valid according to the analysis in [41]. 
A more complicated equivalent circuit can be used for composites with a mixed layered-bulk structure, e.g., a filler polymer composite on a corrosion-active substrate or for coatings with protector and active additives [33, 42-44].

However, it should be taken into account that the assignment of elements in complex equivalent circuits to particular processes in coatings becomes unobvious due to their mutual interference.

Some authors suggest introducing additional elements, including a Warburg element for coatings with protector additives [45], particularly at large exposure times [46].

Mathematical simulation of an increase in the coating thickness (at constant porosity and defectivity) shows that the thicker the coating, the less pronounced the faradaic process of substrate corrosion in Bode diagrams and hodographs [27]. Further studies of thicker multilayer coatings demonstrated the necessity of additional consideration of a decrease in the through porosity owing to the closure of defects.

With account for the above, some examples of ECs are shown below for some typical systems whose EIS data are shown above (Figures 2-10).

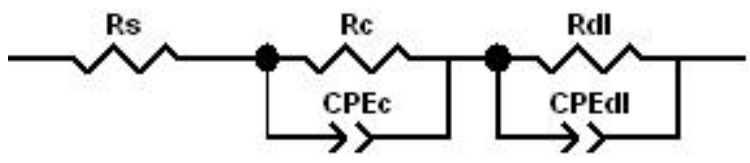

Figure 15. Equivalent circuit for the calculation of an inert R-5095 epoxy coating applied directly on a steel substrate after exposure to $3 \% \mathrm{NaCl}$ for 200 days.

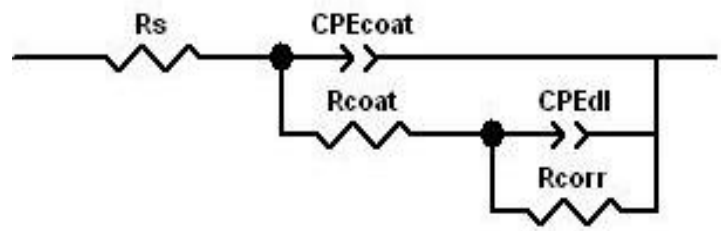

Figure 16. Equivalent circuit for the calculation of a Zn-filled M-01 epoxy primer coat on a steel substrate after exposure to $3 \% \mathrm{NaCl}$ for 100 days.

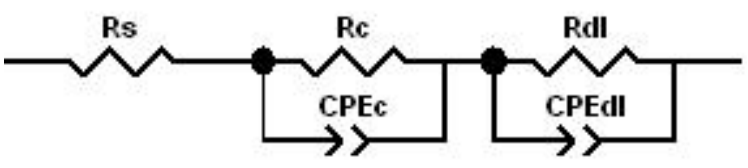

Figure 17. Equivalent circuit for the calculation of an inert three-layer epoxy coating applied directly on a steel substrate after exposure to $30 \% \mathrm{H}_{2} \mathrm{SO}_{4}$ at $20^{\circ} \mathrm{C}$ for $962 \mathrm{~h}$. 


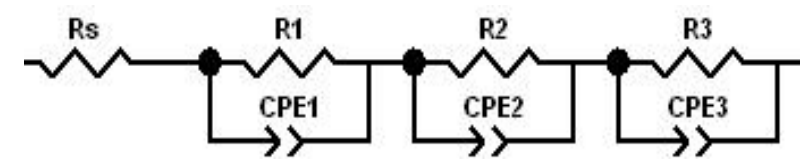

Figure 18. Equivalent circuit for the calculation of the system of Zn-filled M-017B epoxy primer coat+inert R-5095 epoxy coating on a steel substrate after exposure to $3 \% \mathrm{NaCl}$ for 200 days.

\subsection{Calculation of the physicochemical parameters of coatings}

The existing theoretical concepts allow estimating the principal physicochemical parameters of protective coatings based on a given equivalent circuit [47].

This work discusses the possibility of assessing the defect parameters in the coating bulk and also on the surface of both the coating and the metal being protected. Such estimates can be performed based on both the capacitance and resistance of the coating and the boundary layer.

\subsubsection{Integral sorption of a corrosive medium}

It is known that corrosive aqueous media can be sorbed by polymer composites both by the mechanism of molecular dissolution in the polymer base and by cluster formation in pores of various nature and size. As applied to anticorrosive coatings, one should take into account that in the case of exposure to corrosive media, partially soluble products of subfilm corrosion favoring formation of osmotic cells can also serve as sorption centers.

The theoretical basis for the calculation of sorption characteristics relies on the relationship between electric capacitance $\left(C_{\mathrm{c}}\right)$ of the polymer coating and variation in the dielectric constant of the coating material $(\varepsilon)$ owing to the penetration of the corrosive medium:

$$
C_{\mathrm{c}}=\frac{\varepsilon \varepsilon_{0} A}{h}
$$

where $\varepsilon_{0}=8.85 \cdot 10^{-12} \mathrm{~F} / \mathrm{m}$ is the dielectric constant of vacuum; $A$ is the working electrode surface area; and $h$ is the coating thickness.

A sorption-related increase in dielectric permeability $\varepsilon$ of polymers has been shown experimentally not only for water [48] but also for electrolyte solutions [49].

The mass sorption of water by coatings can be calculated by the empirical BrasherKingsbury relationship based on data on the variation of electric capacitance [50, 51]:

$$
\Phi=\frac{\log \left(\frac{C_{t}}{C_{0}}\right)}{\log \varepsilon_{\mathrm{H}_{2} \mathrm{O}}}
$$


where $\Phi$ is the mass sorption, $\%$; $C_{t}$ is the coating capacitance in the case of full saturation; $C_{0}$ is the initial coating capacitance at $t=0$; and $\varepsilon_{\mathrm{H}_{2} \mathrm{O}}$ is the dielectric constant of water $(\sim 80$ at $\left.t=20^{\circ} \mathrm{C}\right)$.

The correctness of this method is supported by the fact that the time point when a coating is saturated with water coincides with the time of reaching a saturation by both the coating capacitance and resistance [52].

As a potentially complicating factor in using the data on capacitance variation, one should point out that the spatial inhomogeneity of water sorption can result in a deviation from pure capacitance [53].

Figure 19 below shows the impedance hodographs for a thin-layer $(h=100 \mu \mathrm{m})$ inert R-5095 epoxy coating applied directly on steel and platinum, which is the simplest protective coating model. Table 1 demonstrates changes in high-frequency (HF) capacitance and the calculated values of integral sorption of an aqueous solution of the electrolyte by the coating material.

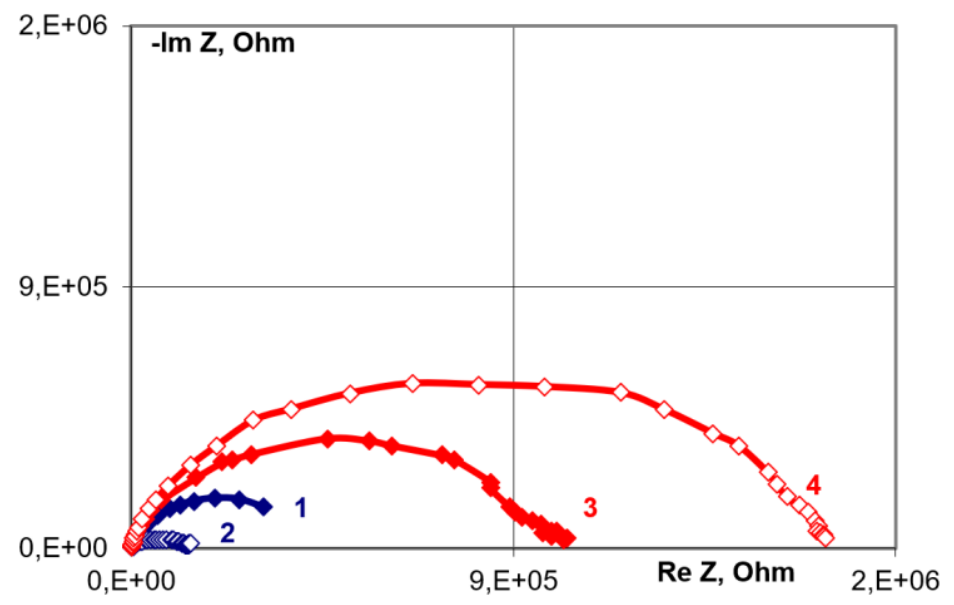

Figure 19. Impedance hodographs of R-5095 coating applied directly on different substrates after exposure to $3 \% \mathrm{NaCl}$ : (1) 30 days on steel; (2) 200 days on steel; (3) 30 days on platinum; (4) 200 days on platinum.

Table 1. Variation in the electric capacitance and estimation of mass sorption by ROKOR-5095 inert epoxy coating applied on steel and platinum substrates after exposure to $3 \% \mathrm{NaCl}$ for 200 days at $25^{\circ} \mathrm{C}$.

\begin{tabular}{ccc}
\hline \multirow{2}{*}{ Parameter } & \multicolumn{2}{c}{ Substrate } \\
\cline { 2 - 3 } & Platinum & St3 \\
\hline Initial coating capacitance, F & $4.08 \cdot 10^{-9}$ & $4.09 \cdot 10^{-9}$ \\
Coating capacitance after 200 days of sorption, F & $6.86 \cdot 10^{-9}$ & $7.80 \cdot 10^{-9}$ \\
Mass sorption, wt.\% (calculated by Equation (1)) & 11.8 & 14.7 \\
Mass sorption, wt. \% (weight gain method) & 11.5 & 11.5 \\
\hline
\end{tabular}


As one can see from the presented results (Table 1), the calculated sorption value on a corrosion-inert Pt substrate (11.8\%) almost coincides with the sorption of free films determined using the weight method (11.5\%). It is noteworthy that the sorption on a corroding steel substrate is somewhat higher $(15 \%)$.

This fact allows one to conclude that the method enables obtaining rather accurate estimates of the sorption of the medium by the coating film and, moreover, evaluating the effect of the metal substrate type due to additional sorption presumably on osmotically active substrate corrosion products.

Thus, this nondestructive method can be used for estimation of the integral sorption of thin-layer industrial polymer coatings both due to molecular solubility in the polymer base and due to formation of clusters and phase inclusions in pores.

\subsubsection{Estimation of the defectivity of paint coatings}

For anticorrosion protective coatings, it is crucially important to estimate the bulk defectivity in the form of through pores and especially adhesion-corrosion defects.

Such defects can be estimated from EIS data based on the analysis of equivalent circuits with elements simulating the corresponding defects.

In the case of highly porous coatings in the Mansfeld model (Figure 12), film resistance $R_{\text {coat }}$ is mainly determined by the phase transfer in the pores. The overall resistance of through pores $\left(R_{\mathrm{po}}\right)$ can be represented as:

$$
R_{\mathrm{po}}=\frac{R_{\mathrm{po}}^{0}}{S_{\mathrm{d}}}=\frac{\rho h}{S_{\mathrm{d}}}
$$

where $\rho$ is the specific pore resistance; $h$ is the coating thickness; $S_{\mathrm{d}}$ is the overall pore surface area.

One can see that the resistance of transfer across the pores drops with a decrease in the specific resistance of the pore electrolyte and with an increase in overall porosity.

Assuming [27] that the local subfilm corrosion process starts and predominantly develops directly under pores, one can obtain the relationship between the variation in the resistance and capacitance of the subfilm corrosion zone.

Resistance variation in the zone of the start of corrosion damage under a pore can be represented as:

$$
R_{\mathrm{dl}}=\frac{R_{\mathrm{dl}}^{0}}{A_{\mathrm{dl}}} \text { or } A_{\mathrm{dl}}=\frac{R_{\mathrm{dl}}^{0}}{R_{\mathrm{dl}}}
$$

where $R_{\mathrm{dl}}$ is the polarization resistance of a section of the coating/metal boundary where the peeling/corrosion process has started; $R_{\mathrm{dl}}^{0}$ is the polarization resistance in case of complete coating peeling $\left(A_{\mathrm{dl}}=1\right) ; A_{\mathrm{dl}}$ is the current area of the peeling or corrosion zone.

For the corresponding change in the capacitance of the corroding area, we have: 


$$
C_{\mathrm{dl}}=C_{\mathrm{dl}}^{0} A_{\mathrm{dl}}
$$

where $C_{\mathrm{dl}}$ is the capacitance of the corrosion zone; $C_{\mathrm{dl}}^{0}$ is the double layer capacitance on a substrate with complete peeling $\left(A_{\mathrm{dl}}=1\right)$.

Combining expressions for resistance (2) and capacitance (3) in the zone near the pore, we obtain:

$$
R_{\mathrm{dl}}=\frac{K}{C_{\mathrm{dl}}}
$$

The concepts considered above were tested with experimental EIS data for thin-layer inert epoxy coating ROKOR-5095 applied without a primer onto metallic steel and platinum substrates after exposure to $3 \% \mathrm{NaCl}$ (Figure 19).

The calculated active layer resistance and capacitance parameters are presented below (Figures 20,21), and the correlation in the coordinates of Equation (4) is shown in Figure 22.

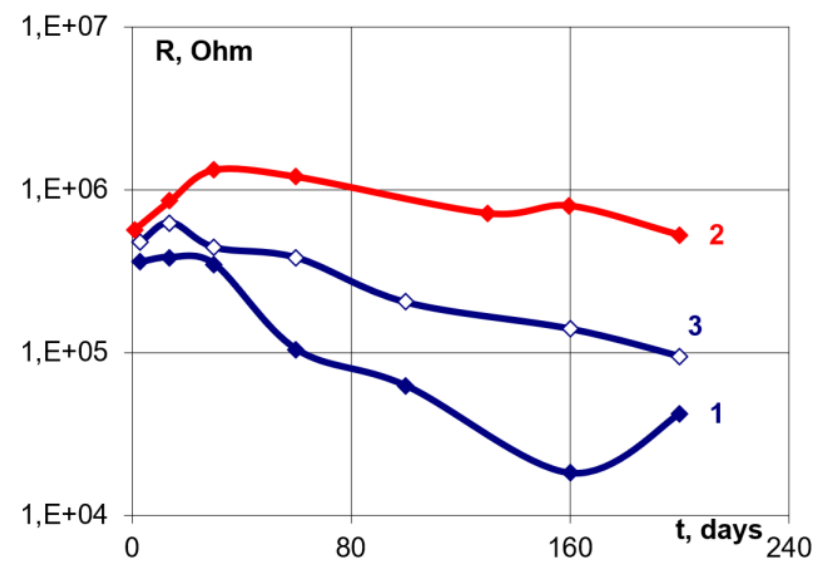

Figure 20. Kinetic dependences of coating resistance $R_{\mathrm{c}}$ on steel (1) and on platinum (2) and electric double layer resistance $R_{\mathrm{dl}}$ on steel (3) for R-5095 epoxy coating.

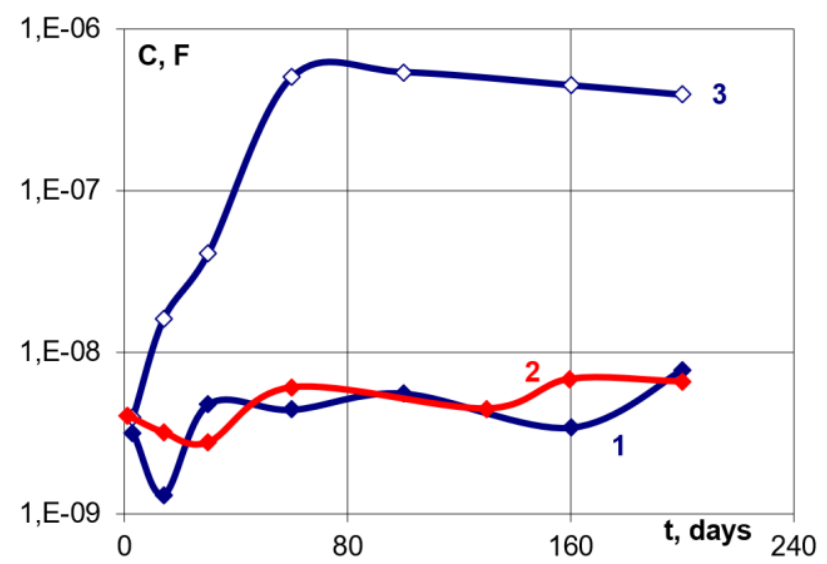

Figure 21. Dependences of kinetic capacitances $C_{\mathrm{c}}$ of the coating on steel (1) and on platinum (2) and electric double layer capacitance $C_{\mathrm{dl}}$ on steel (3) for R-5095 epoxy coating. 


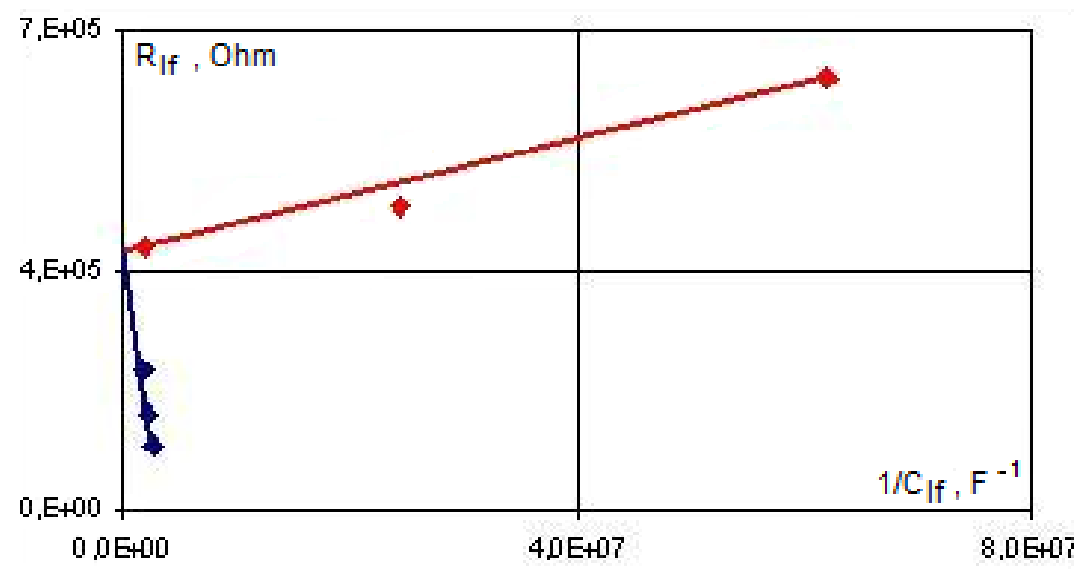

Figure 22. Dependence of resistance on the inverse capacitance of the faradaic low-frequency (LF) process for R-5095 coating applied on a steel substrate in the course of treatment in 3\% $\mathrm{NaCl}$.

The results of testing the thin inert coatings show that:

1. There is a certain relationship between the resistance and inverse capacitance of the faradaic LF process. However, this relationship is more complicated than that predicted by the Mansfeld-Titz model and is non-linear in the whole time range.

2. The available experimental data (Figure 20 and Figure 21) do not allow confirming the above initial statement that the local corrosion subfilm process develops under pores, and the dependence between $R_{\mathrm{dl}}$ and $1 / C_{\mathrm{dl}}$ predicted by the above model is not confirmed either.

3. Experimental data allow distinguishing two time ranges, each of which can be described by a linear dependence, but such lines do not pass through the coordinate system's origin:

$$
R_{\mathrm{dl}}=\frac{K}{C_{\mathrm{dl}}}+\mathrm{const}
$$

The observed discrepancies between the experimental data and the discussed model representations of kinetic dependences are apparently related to the presence of additional mechanisms of subfilm corrosion development for thin-film coatings.

In view of this, one should expect that, as opposed to thin-film coatings, the mechanism of subfilm corrosion development for multilayer thick protective coatings can be more unambiguous.

\subsection{Subfilm corrosion for thick multilayer protective coatings}

The model of subfilm corrosion under thick and multilayer protective coatings with negligible through porosity [54] allows relating the changes in integral resistance $R_{\mathrm{dl}}$ to the characteristics of the subfilm corrosion process (Figure 23). 
Within the model of such coatings, one can distinguish two types of areas of the subfilm corrosion process development, namely, areas with the initial structure that preserves adhesion to the substrate and areas of local development of the subfilm corrosion process.

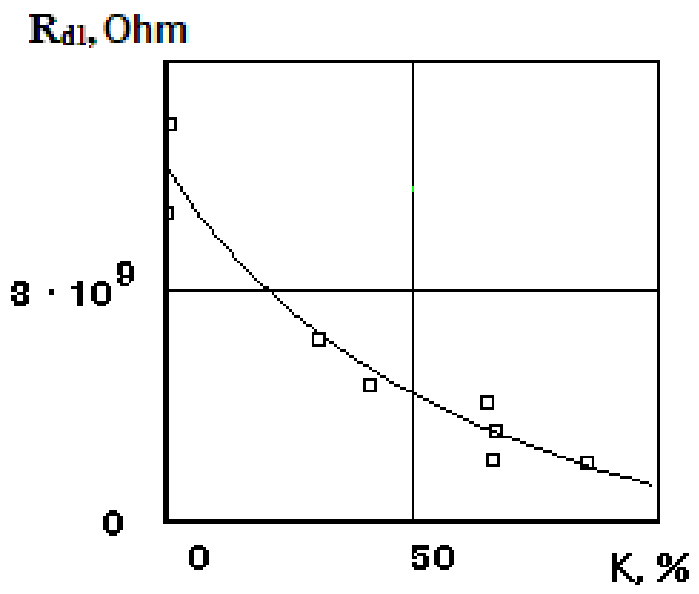

Figure 23. Correlation of the transition layer resistance $\left(R_{\mathrm{dl}}\right)$ after exposure in water with the fraction of corrosion damage for a three-layer epoxy coating on a steel substrate. The coating thickness is $450 \pm 50 \mu \mathrm{m}$.

It is assumed that the resistance $R_{\mathrm{dl}}$ of areas with subfilm corrosion is lower than that of adhered areas owing to the partial solubility of corrosion products. Therefore, the integral resistance of the studied coating surface must also change when the ratio between the adhered areas and areas with subfilm corrosion is varied. Then:

$$
\frac{1}{R_{\mathrm{dl}}(1-K)}=\frac{S}{\rho_{\text {init }}}+\frac{S}{\rho_{\text {corr }}} \times\left(\frac{K}{1-K}\right)
$$

where $K$ is the fraction of corroded surface, $S$ is the coating (cell) surface area, $\rho_{\text {init }}$ is the initial specific resistance of the adhered transition layer, and $\rho_{\text {corr }}$ is the specific resistance of the transition layer in the areas with subfilm corrosion.

As follows from (5), a correlation must be observed between the value of integral resistance $R_{\mathrm{dl}}$ and the corrosion damage area (fraction of the corroded surface) that corresponds to a straight line in reduced coordinates, in agreement with the experimental results for a multilayer coating (Figure 24).

Calculation of the values of specific resistances of the transition layer for the initial coating and subfilm corrosion sites yields the values of $3 \cdot 10^{10}$ and $1 \cdot 10^{10} \mathrm{Ohm} \cdot \mathrm{cm}$, respectively, which agrees with the initial assumption on the lower resistance of areas with subfilm corrosion. 


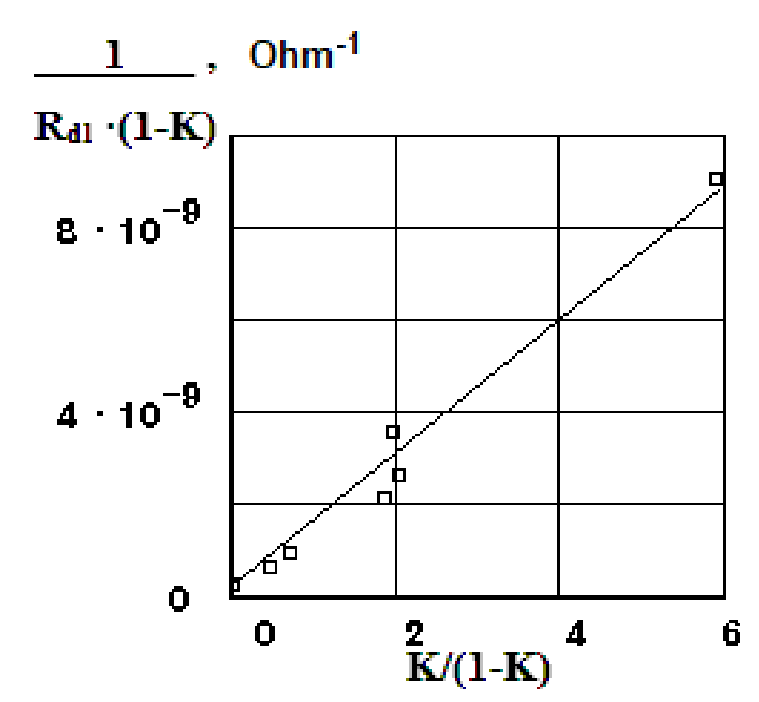

Figure 24. Dependence of reduced inverse transition layer resistance $R_{\mathrm{dl}}$ after exposure in water on the relative fraction of subfilm corrosion damage of the steel substrate for a threelayer epoxy coating in the coordinates of equation (5). The coating thickness is $450 \pm 50 \mu \mathrm{m}$.

The model considered can be used as a base for estimating subfilm corrosion from parallel results of EIS studies of coatings under industrial and laboratory conditions. The method of local electrochemical impedance spectroscopy (LEIS) for localization of subfilm corrosion and zones of coating peeling could be a useful addition for using EIS for such testing $[55,56]$.

\section{Conclusion}

Thus, the analysis of the application of various electrochemical and electrophysical methods of nondestructive testing of protective polymer coatings in various corrosive media made in this article allows us to single out the electrochemical impedance (EIS) technique.

This method is promising not only for calculating the basic physicochemical characteristics of coatings in corrosive media, but also for nondestructive testing of their defective structure and the extent of subfilm corrosion, even directly at industrial sites. It appears that the results of this work can be useful for devices for nondestructive EIS analysis of the efficiency of operating protective coatings that are currently being developed.

\section{References}

1. G. Smitch, M. Schütze, G. Hays, W. Burns, E.-H. Han, A. Pourbaix and G. Jacobson, The world corrosion organization, May 2009, 44 pp.

2. I.V. Semenova, G.M. Florianovich and A.V. Khoroshilov, Corrosion and Corrosion Protection, 2010, Moscow: FIZMATLIT, 416 pp. (in Russian).

3. E. Kunze, Korrosion und Korrosionsschutz, Wiley-VCH-2001, 3, 1680 pp. (in German). 
4. V.A. Golovin, A.B. Il'in, V.A. Shchelkov, S.A. Dobriyan, S.A. Tyurina and I.I. Reformatskaya, Concept of composite polymer coatings for oil and gas media, Korroz.: Mater., Zashch. (Corrosion: Materials, Protection), 2015, no. 1, 14-22.

5. V.A. Golovin, Multilayer protective polymer coatings. Penetrability in highly corrosive media, Korroz.: Mater., Zashch. (Corrosion: Materials, Protection), 2004, no. 6, 3646.

6. V.A. Golovin, A.B. Il'in, A.D. Aliev and V.A. Rabinkov, Mass Transfer of PhosphorusContaining Corrosion Inhibitors in Epoxy Protective Coatings, Prot. Met. Phys. Chem. Surf., 2019, 55, no. 7, 1345-1351. doi: $10.1134 /$ S2070205119070050

7. N.P. Zhuk, Kurs teorii korrozii $i$ zashchity metallov (A Course in Theory of Metal Corrosion and Protection), Moscow: Metallurgy, 1976, 164 (in Russian).

8. V. Sorokov, S.N. Stepin, A.A. Kayumov, S.A. Sitnov and O.P. Kuznetsova, Methods of assessment of anticorrosion efficiency of lacquer-and-paint coatings, Vestn. Kazan. Tekhnol. Univ., 2012, 15, no. 24, 68-75.

9. F. Mansfeld, H. Shih, H. Greene and C.H. Tsai, Electrochemical Impedance: Analysis and Interpretation, Eds.: J. Scully, D.C. Silverman and M. Kendig, 1993, 37, ASTM, Philadelphia, PA. doi: 10.1520/STP1188-EB

10. RD GP 39-30-1093-84, Rosneft, Method of accelerated estimation of lifetime of polymer coatings for corrosion protection of oil and gas equipment developed by Institute of Problems of Transport of Power Resources, Bashkortostan, Russia, and Gubkin State Academy of Oil and Gas, Moscow, Russia. agsmetalgroup.ru/publ/zashhita_neftjanykh_rezervuarov_ot_korrozii/kontrol_kachestva_nanesennykh_zashhitnykh_pokrytij/21-1-0-129. https://www.russiangost.com/p377409-rd-39-30-1093-84.aspx

11. V.A. Golovin, H.V. Pechnikov， S.B. Kapranov， N.N. Davidenko, A.M. Nemytova, P.D. Bachinsky and V.A. Trembovler, Using an eddy-current technique for studying local corrosion and scale formation on the walls of heat-exchanger tubes, Prot. Met. Phys. Chem. Surf., 2017, 52, no. 7, 1197-1204. doi: 10.1134/S2070205116070066

12. V.G. Gerasimov, V.V. Kluyev and V.E. Shaternikov, Metody $i$ pribory elektromagnitnogo kontrolya (Methods and Devices of Electromagnetic Control), Ed.: V.E. Shaternikov, Spektr, Moscow, 2010 (in Russian).

13. V.P. Lunin, Dvukhshagovyi algoritm konechno-elementnogo resheniya zadach elektromagnitnogo kontrolya. Vikhretokovyi control' (Two-stage algorithm of finiteelement solution of problems of electromagnetic control. Eddy current method), Defektoskopiya, 2006, 62-69 (in Russian).

14. G. Pichenot, F. Buvat, V. Maliot and H. Voillaume, Eddy current modeling for nondestructive testing, 16 World Conference On Nondestructive Testing, Montréal, 2004. 
15. V.A. Golovin, N.V. Pechnikov, V.A. Shchelkov and A.Yu. Tsivadze, Determination of the Life Cycle of Heat-Exchange Tubes of Vapor Condensers on the Basis of Statistical Analysis of Local Pitting Corrosion According to Data of Eddy Current Testing, Prot. Met. Phys. Chem. Surf., 2018, 54, no. 6, 1221-1232. doi: 10.1134/S2070205118060138

16. V.A. Golovin, S.A. Dobriyan, V.A. Shchelkov and A.I. Shcherbakov, Electrochemical Properties of Zn-rich Primers and Composite Coatings on Various Metal Substrates, Int. J. Corros. Scale Inhib., 2020, 9, no. 1, 56-73. doi: 10.17675/2305-6894-2020-9-1-4

17. W. Trabelsi, P. Cecilio, M.G.S. Ferreira and M.F. Montemor, Electrochemical assessment of the self-healing properties of Ce-doped silane solutions for the pretreatment of galvanised steel substrates, Prog. Org. Coat., 2005, 54, no. 4, 276-284. doi: 10.1016/j.porgcoat.2005.07.006

18. A.A. Chirkunov and M.L. Zheludkevich, Corrosion inhibition of Elektron WE43 magnesium alloy in $\mathrm{NaCl}$ solution, Int. J. Corros. Scale Inhib., 2018, 7, no. 3, 376-389. doi: $10.17675 / 2305-6894-2018-7-3-8$

19. M.L. Zheludkevich, S.K. Poznyak, L.M. Rodrigues, D. Raps, T. Hack, L.F. Dick, T. Nunes and M.G.S. Ferreira, Active protection coatings with layered double hydroxide nanocontainers of corrosion inhibitor, Corros. Sci., 2010, 52, 602-611. doi: $\underline{10.1016 / j . c o r s c i .2009 .10 .020}$

20. O.V. Karavai, A.C. Bastos, M.L. Zheludkevich, M.G. Taryba, S.V. Lamaka and M.G.S. Ferreira, Localized electrochemical study of corrosion inhibition in microdefects on coated AZ31 magnesium alloy, Electrochim. Acta, 2010, 55, no. 19, 5401-5406. doi: 10.1016/j.electacta.2010.04.064

21. A.M. Simões, A.C. Bastos, M.G.S. Ferreira, Y. González-García, S. González and R.M. Souto, Use of SVET and SECM to study the galvanic corrosion of an iron-zinc cell, Corros. Sci., 2007, 49, no. 2, 726-739. doi: 10.1016/j.corsci.2006.04.021

22. S.V. Lamaka, R.M. Souto and M.G.S. Ferreira, In-situ visualization of local corrosion by Scanning Ionselective Electrode Technique (SIET), in Microscopy: Science, Technology, Applications and Education, Edition 2010, Ed.: A.M. Vilas, Formatex Research Center, Badajoz, Spain, 2010, 3, 2162-2173.

23. C.J. Lin, R.G. Du and T. Nguyen, In-Situ Imaging of Chloride Ions at the Metal/Solution Interface by Scanning Combination Microelectrodes, Corrosion, 2000, 56, 41-47. doi: $10.5006 / 1.3280521$

24. M. Taryba, S.V. Lamaka, D. Snihirova, M.G.S. Ferreira, M.F. Montemor, W.K. Wijting, S. Toews and G. Grundmeier, The combined use of scanning vibrating electrode technique and micro-potentiometry to assess the self-repair processes in defects on "smart" coatings applied to galvanized steel, Electrochim. Acta, 2011, 56, no. 12, 4475-4488. doi: 10.1016/j.electacta.2011.02.048

25. G. Cai, H. Wang, D. Jiang and Z. Dong, Impedance sensor for the early failure diagnosis of organic coatings, J. Coat. Technol. Res., 2018, 15, no. 6, 1259-1272. doi: $\underline{10.1007 / \mathrm{s} 11998-018-0072-5}$ 
26. F. Mansfeld, Recording and Analysis of AC Impedance Data for Corrosion Studies, Corrosion, 1981, 37, no. 5, 301-307. doi: 10.5006/1.3621688

27. F. Mansfeld, Use of electrochemical impedance spectroscopy for the study of corrosion protection by polymer coatings, J. Appl. Electrochem., 1995, 25, 187-202. doi: $\underline{10.1007 / \mathrm{BF} 00262955}$

28. G. Bierwagen, J. Li, L. He and D. Tallman, Fundamentals of the Measurement of Corrosion Protection and the Prediction of Its Lifetime in Organic Coatings, Proceedings of the Second International Symposium on Service Life Prediction Methodology and Metrologies, Monterey, CA, 1999, Chapter 16, 316-350.

29. S. Shreepathi, P. Bajaj and B.P. Mallik, Electrochemical impedance spectroscopy investigations of epoxy zinc rich coatings: role of $\mathrm{Zn}$ content on corrosion protection mechanism, Electrochim. Acta, 2010, 55, 5129-5134. doi: 10.1016/j.electacta.2010.04.018

30. E. Barsoukov and J.R. MacDonald, Impedance Spectroscopy Theory, Experiment, and Applications, 2nd ed., John Wiley \& Sons, Inc, Hoboken, New Jersey, 2005, 595.

31. ISO 16773-1, 2, 3, 4, Electrochemical impedance spectroscopy (EIS) on high-impedance coated specimens.

32. ISO Standard 16773-2, 2007, Paints and Varnishes-Electrochemical Impedance Spectroscopy (EIS) on High-impedance Coated Specimens-Part 2: Collection of Data, NSAI, Ireland, Dublin, 2007.

33. V.A. Golovin, S.A. Dobriyan, V.B. Lukin and K.V. Kolinenko, On the Choice of an Equivalent Circuit for the Description of Electrochemical Impedance Spectra of $\mathrm{Zn}$ Filled Polymer Primers and Coatings, Prot. Met. Phys. Chem. Surf., 2018, 53, no. 7, 1221-1229. doi 10.1134/S2070205117070061

34. M.M. Verdian, K. Raeissi and M. Salehi, Electrochemical impedance spectroscopy of HVOF-sprayed NiTi intermetallic coatings deposited on AISI 1045 steel, J. Alloys Compd., 2010, 507, no. 1, 42-46. doi: 10.1016/j.jallcom.2010.07.132

35. V.A. Golovin, S.A. Dobriyan and V.E. Kasatkin, Spectroscopy of electrochemical impedance (EIS) of composite polymer coatings on metal substrates, Int. J. Corros. Scale Inhib., 2018, 7, no. 4, 697-709. doi: 10.17675/2305-6894-2018-7-4-15

36. C.H. Hsu and F. Mansfeld, Technical Note: Concerning the Conversion of the Constant Phase Element Parameter $\mathrm{Y}_{0}$ into a Capacitance, Corrosion, 2001, 57, no. 9, 747-748. doi: $10.5006 / 1.3280607$

37. C. Verma, M.A. Quraishi, K. Kluza, M. Makowska-Janusik, L.O. Olasunkanmi and E.E. Ebenso, Corrosion inhibition of mild steel in $1 \mathrm{M} \mathrm{HCl}$ by D-glucose derivatives of dihydropyrido [2,3-d:6,5-d'] dipyrimidine-2,4,6,8(1H,3H, 5H,7H)-tetraone, Sci. Rep., 2017, 7, 44432. doi: 10.1038/srep44432

38. https://www.gamry.com/assets/Uploads/resources/The-Basics-of-EIS-Part-4.pdf 
39. O.L. Zalesova, O.V. Yaroslavtseva, A.S. Solov'ev and V.M. Rudoi, Using Impedance Spectroscopy for Determination of the Effect of Bulk Concentration of the Dye on Structural Properties of the Epoxy Coating, Vestn. Kazan. Tekhnol. Univ., 2014, 17, no. 14, 136-139.

40. P. Martin, Sum rules Kramers-Kronig relations and transport coefficients in charged systems, Phys. Rev., 1967, 161, 143. doi: 10.1103/PhysRev.161.143

41. P. Agarwal, M.E. Orazem and L.H. Garcia-Rubio, Constant-phase-element behavior caused by resistivity distributions in films I. Theory, J. Electrochem. Soc., 1992, 139, 1917-1927.

42. E.S. Buyanova and Yu.V. Emel'yanova, Electrochemical impedance, Ekaterinburg: Izd. Uralskogo Gosudarstvennogo Universiteta, 2008, 95 (in Russian).

43. M.F. Montemor, R. Pinto and M.G.S. Ferreira, Chemical composition and corrosion protection of silane films modified with $\mathrm{CeO}_{2}$ nanoparticles, Electrochim. Acta, 2009, 54, 5179-5189. doi: $10.1016 /$ j.electacta.2009.01.053

44. C. Gabrielli, Use and application of electrochemical impedance techniques, Farnborough, 1990, 78 pp.

45. M. Yaganeh, N. Asadi, M. Omidi and M. Mahdavian, An investigation on the corrosion behavior of the epoxy coating embedded with mesoporous silica nanocontainer loaded with sulfamethazine inhibitor, Prog. Org. Coat., 2019, 128, 75-81. doi: 10.1016/j.porgcoat.2018.12.022

46. T.N. Ostanina, Elektrokhimicheskoe povedenie i fiziko-khimicheskie svoistva metallonapolnennykh pokrytii (Electrochemical behavior and physicochemical properties of metal-filled coatings), Doctor Sci. (Chem.) Thesis, Ekaterinburg, 2003, 226 (in Russian).

47. D. Ramesh and T. Vasudevan, Evaluation of corrosion stability of water soluble epoxyester primer through electrochemical studies, Mater. Sci. Appl., 2012, 3, 333-347. doi: $\underline{10.4236 / \mathrm{msa} .2012 .36049}$

48. P. Molera, J. Montoya and M. Del Valle, Zinc Phosphate as Corrosion Inhibitor in Epoxy Paints, Corros. Rev., 2003, 21, no. 4, 349-358. doi: 10.1515/CORRREV.2003.21.4.349

49. A.S.L. Castela, A.M. Simoes and M.G.S. Ferreira, E.I.S. Evaluation of Attached and Free Polymer Films, Prog. Org. Coat., 2000, 38, no. 1, 1-7. doi: 10.1016/S03009440(99)00076-4

50. D.M. Brasher and A.H. Kingsbury, Electrical measurements in the study of immersed paint coatings on metal. I. Comparison between capacitance and gravimetric methods of estimating water uptake, J. Appl. Chem., 1954, 4, no. 2, 62-72. doi: 10.1002/jctb.5010040202

51. J.M. Sykes, A variant of the Brasher-Kingsbury equation, Corros. Sci., 2004, 46, no. 3, 515-517. doi: 10.1016/j.corsci.2003.10.001 
52. M. Bethencourt, F.J. Botana, M.J. Cano, R.M. Osuna and M. Marcos, Degradation mechanism of an acrylic water-based paint applied to steels, Prog. Org. Coat., 2003, 47, no. 2, 164-168. doi: 10.1016/S0300-9440(03)00124-3

53. M. Yaganeh and A. Keyvani, The effect of mesoporous silica nanocontainers incorporation on the corrosion behavior of scratched polymer coatings, Prog. Org. Coat., 2016, 90, 296-303. doi: 10.1016/j.porgcoat.2015.11.006

54. V.A. Golovin and S.A. Dobriyan, EIS studies of protective polymer coatings in sulfuric acid on low-carbon steel, Korroz.: Mater., Zashch. (Corrosion: Materials, Protection), 2020, no. 6, 33-38.

55. J.B. Jorcin, E. Aragon, C. Merlatti and N. Pebere, Delaminated areas beneath organic coating: a local electrochemical impedance approach, Corros. Sci., 2006, 48, no. 7, 1779-1790. doi: $10.1016 /$ j.corsci.2005.05.031

56. C.F. Dong, A.Q. Fu, X.G. Li and Y.F. Cheng, Localized EIS characterization of corrosion of steel at coating defect under cathodic protection, Electrochim. Acta, 2008, 54, no. 2, 628-633. doi: 10.1016/j.electacta.2008.07.016 